This item was submitted to Loughborough's Research Repository by the author.

Items in Figshare are protected by copyright, with all rights reserved, unless otherwise indicated.

\title{
Preparation and characterization of benzoxazine based nanocomposites: comprehensive study in curing kinetics and enhanced thermal stabilities
}

PLEASE CITE THE PUBLISHED VERSION

http://dx.doi.org/10.1002/app.41903

\section{PUBLISHER}

(c) Wiley Periodicals

\section{VERSION}

AM (Accepted Manuscript)

\section{PUBLISHER STATEMENT}

This work is made available according to the conditions of the Creative Commons Attribution-NonCommercialNoDerivatives 4.0 International (CC BY-NC-ND 4.0) licence. Full details of this licence are available at: https://creativecommons.org/licenses/by-nc-nd/4.0/

\section{LICENCE}

CC BY-NC-ND 4.0

\section{REPOSITORY RECORD}

Lin, Yue, Corinne A. Stone, Steve J. Shaw, and Mo Song. 2015. "Preparation and Characterization of Benzoxazine Based Nanocomposites: Comprehensive Study in Curing Kinetics and Enhanced Thermal Stabilities". figshare. https://hdl.handle.net/2134/17912. 
Preparation and characterization of benzoxazine based nanocomposites: Comprehensive study in curing kinetics and enhanced thermal stabilities

Y.Lin and M. Song*

Department of Materials, Loughborough University, Loughborough LE11 3TU, UK

C.A. Stone, S.J.Shaw

Dstl, Porton Down, Salisbury SP4 0JQ, UK

m.song@lboro.ac.uk

\section{Abstract}

Several benzoxazine (BEN) based nanocomposites incorporated with a polyhedral oligomeric silsesquioxane (POSS), carbon nanotubes (CNTs), and clays, were prepared successfully. The influences of the nanofillers on the curing dynamics, network formation, and thermal stability of the BEN were investigated comprehensively. Incorporation of the POSS and clays did not show significant accelerating effect on the cure of the BEN, whilst the peak temperature of the cure decreased by $27^{\circ} \mathrm{C}$, with the addition of $2 \mathrm{wt} \%$ MWCNT-OH. All the functionalised nanofillers reacted with the BEN during the cure. Furthermore, the incorporation of the nanofillers showed good improvement on BEN thermal stability. For the BEN/clay nanocomposites, an increase of $70^{\circ} \mathrm{C}$ at the onset temperature and an increase of $336{ }^{\circ} \mathrm{C}$ at the half-life decomposition temperature were observed with the addition of $5 \mathrm{wt} \%$ 30B clay in nitrogen atmosphere. With the incorporation of $5 \mathrm{wt} \%$ POSS, the half-life decomposition temperature increased by $34{ }^{\circ} \mathrm{C}$ in air atmosphere, and the half-life of decomposition and char yield enhanced by $280^{\circ} \mathrm{C}$ and $13 \mathrm{wt} \%$ in nitrogen atmosphere. With the incorporation of $4 \mathrm{wt} \%$ MWCNT, both of the onset and half-life decomposition temperatures increased by around $40{ }^{\circ} \mathrm{C}$ in air atmosphere. Under nitrogen atmosphere, with the addition of $4 \mathrm{wt} \%$ MWCNT, the onset decomposition temperature of BEN increased by $74{ }^{\circ} \mathrm{C}$. For the $4 \mathrm{wt} \%$ MWCNT-COOH/BEN nanocomposite, the half-life of decomposition and char yield at $800{ }^{\circ} \mathrm{C}$ increased by $286{ }^{\circ} \mathrm{C}$ and $14 \mathrm{wt} \%$, respectively.

Key words: benzoxazine, POSS, CNT, clay, curing dynamics, network formation, 
thermal stability.

\section{Introduction}

Recently, polybenzoxazines, a newly developed class of polymerised phenolic system, have received a wide range of interest, due to their good mechanical performance, molecular design flexibility, and thermal and flame retardant properties. More importantly, polybenzoxazines under spotlight is that it overcomes the problems of traditional novolac and resole phenolic systems, such as, poor shelf life. ${ }^{1}$ The polybenzoxazine also performs several unique features, (a) near-zero shrinkage upon curing, (b) low water absorption, (c) $\mathrm{T}_{\mathrm{g}}$ much higher than cure temperature for some polybenzoxazine based materials, (d) relatively good thermal stability, (e) no strong acid catalysts required for curing, and (f) release of no by-products during curing. ${ }^{2}$ Although polybenzoxazines possess a lot of unique features, there are some shortcomings, for example, low processability, and high curing temperature. In order to overcome these shortages during applications, benzoxazine is usually mixed with other polymers and fillers to prepare polymer blends and composites. It has been reported that benzoxazine was blended with rubber ${ }^{3-6}$ and polycarbonate ${ }^{7}$ to improve toughness, poly (e-caprolactone) (PCL) $)^{8,9}$ to improve processability, polyurethane $(\mathrm{PU})^{10,11}$, and epoxy ${ }^{12-15}$. Apart from polymer blends, the influence of the incorporation of nanofillers on properties of benzoxazine has been studied by a few groups. Huang et al. ${ }^{16}$ prepared polybenzoxazine/POSS nanocomposites through the reactions of a multifunctional vinyl-terminated benzoxazine-POSS with a benzoxazine monomer at various compositional ratios. The mobility of the benzoxazine network was significantly hindered by the incorporation of the silsesquioxane core units. Furthermore, the thermal stability and mechanical properties of the nanocomposites were gradually improved with the increasing POSS content. Agag and Takeichi ${ }^{17}$ demonstrated the preparation of polybenzoxazine-clay nanocomposites by the in-situ polymerization of allyl functionalized benzoxazine monomer, in the presence of two different types of organoclay. The glass transition temperature $\left(\mathrm{T}_{\mathrm{g}}\right)$ of the nanocomposites decreased firstly, and then increased with the increasing organoclay content. These results implied a change of curing mechanism 
and network formation of the benzoxazine with the incorporation of organoclay. Furthermore, the thermal stability of the nanocomposites was better than that of the neat resin. Wang et al. ${ }^{18}$ functionalized multi-walled carbon nanotubes (MWCNTs) using benzoxazine-containing compound (BPA-FBz) and polymer (PFBz) as modifiers through a Diels-Alder reaction. They then fabricated MWCNT-FBz and MWCNT-PFBz cross-linked nanomaterials by using press moulding and other thermal-forming processes. The surface electrical conductivities and electrical conductivities of the crosslinked pellets of MWCNT-FBz and MWCNT-PFBz were measured as $0.05 \mathrm{~S} \mathrm{~cm}^{-1}$ and $7 \times 10^{-5} \mathrm{~S} \mathrm{~cm}^{-1}$. It is believed that the attractive properties were attributed to the good compatibility between the polybenzoxazine matrix and MWCNT-FBz.

Although progress has been made, few groups have comprehensively focused on the curing kinetics and network formation of benzoxazine based nanocomposites. This is vitally interesting and important, particularly for thermoset based nanocomposites. For example, the processing ability and properties of thermoset based nanocomposites depends on various factors, such as the composition of nanocomposites, dispersion of nanofillers, and influence of the nanofillers on the cross-linking reaction. In order to develop high performance benzoxazine based nanocomposites, a clear understanding of curing dynamics and network formation in the benzoxazine resin during cure is essential, so that the properties of the benzoxazine based nanocomposites can be subsequently designed or controlled. On the other hand, in order to meet the ever-increasing demand for thermal stability of benzoxazine, it is very important to study the thermal decomposition of the benzoxazine and its nanocomposites in system. Thus, in this work, the curing dynamic and network formation of the benzoxazine incorporated with several nanofillers were studied. The influence of the nanofillers on the thermal stability of the benzoxazine was studied systematically as well.

\section{Experimental}

\section{Materials}


Araldite ${ }^{\circledR}$ MT 35600 CH Bisphenol-A Benzoxazine resin (BEN) was provided by Huntsman Ltd. TriSilanolPhenyl POSS $\left(\mathrm{C}_{42} \mathrm{H}_{38} \mathrm{O}_{12} \mathrm{Si}_{7} \mathrm{MW}=931.34 \mathrm{~g} / \mathrm{mol}\right)$ was purchased from Hybrid Plastics Inc. The unmodified sodium clay (Cloisite ${ }^{\circledR} \mathrm{Na}+$ ) and the organoclay (Cloisite ${ }^{\circledR}$ 20A and Cloisite ${ }^{\circledR}$ 30B) were purchased from Southern Clay Products, Inc. The modifier for Cloisite ${ }^{\circledR} 20 \mathrm{~A}$ is dimethyl, dehydrogenated tallow, and quaternary ammonium (2M2HT). For Cloisite ${ }^{\circledR} 30 \mathrm{~B}$, it is methyl, tallow, bis-2-hydroxyethyl, quaternary ammonium (MT2EtOH). The pristine multi-walled carbon nanotube (MWCNT), functionalised multi-wall carbon nanotubes (MWCNT-OH and MWCNT-COOH), and functionalised single-wall carbon nanotube (SWCNT-OH) were purchased from Chengdu Institute of Organic Chemistry, Chinese Academy of Science. The multi-wall carbon nanotubes (MWCNTs) have a length of approximate $50 \mu \mathrm{m}$ and a diameter of $8-15 \mathrm{~nm}$. For the hydroxyl functionalised single-walled carbon nanotube used (SWCNT-OH), the length is between $5 \mu \mathrm{m}$ to $30 \mu \mathrm{m}$, and the diameter is 1 to $2 \mathrm{~nm}$. All the solvents used were purchased from Sigma-Aldrich Ltd. UK.

\section{Preparation of BEN mixtures incorporated with the nanofillers}

All BEN mixtures incorporated with clays and POSS were prepared as follows. The BEN resin was firstly held at $100^{\circ} \mathrm{C}$ for 30 minutes with magnetic stirring to remove moisture. Next, the BEN was heated to $120^{\circ} \mathrm{C}$, and calculated amounts of the nanofillers were added into the low viscosity resin to prepare the mixtures. These mixtures were stirred at $120^{\circ} \mathrm{C}$ for 120 minutes. After mixing, all the mixtures prepared were sealed in glass bottles and stored at $-20^{\circ} \mathrm{C}$ for further use.

BEN/CNT mixtures were prepared by the following procedure. CNTs were firstly dispersed in acetone $(1 \mathrm{mg} / 1 \mathrm{ml})$ with assistance of ultrasonication (300 W power, 30 min) at room temperature. The BEN was held at $100^{\circ} \mathrm{C}$ for $30 \mathrm{~min}$ in a vacuum oven to remove moisture, and then was dissolved in acetone. Following this, the BEN/acetone solution was mixed with the BEN/acetone solution with magnetic stirring for 2 hours. The solvent was then volatilised. The resultant was further dried 
in a vacuum oven at $80^{\circ} \mathrm{C}$. The BEN/CNTs mixtures prepared were sealed in glass bottles and stored at $-20^{\circ} \mathrm{C}$ for further use.

\section{Preparation of BEN based nanocomposites}

For all BEN based nanocomposites, the curing procedure is as follows. The BEN based mixtures were firstly pre-cured at $100^{\circ} \mathrm{C}$ for 30 minutes, to make sure all the moisture was removed. Afterwards, the mixtures were cured at $200^{\circ} \mathrm{C}$ for 2 hours, and followed by post-curing at $260^{\circ} \mathrm{C}$ for another 2 hours.

\section{Characterization}

A TA Instruments DSC 2920 calorimeter was employed for Differential Scanning Calorimetry (DSC) and Modulated-Temperature Differential Scanning Calorimetry (MTDSC) measurements. Nitrogen was used as the purge gas $(60 \mathrm{ml} / \mathrm{min})$. All the dynamic experiments were carried out using DSC. Samples were heated from $50^{\circ} \mathrm{C}$ to $350^{\circ} \mathrm{C}$ with a heating rate of $10^{\circ} \mathrm{C} / \mathrm{min}$. For all the quasi-isothermal experiments, MTDSC was employed. Samples were held at selected temperatures with a modulation amplitude of $0.5^{\circ} \mathrm{C}$ per 60 seconds. Fourier transform infrared (FTIR) spectra of the sample coated on $\mathrm{KBr}$ pellet were recorded from $4000 \mathrm{~cm}^{-1}$ to $400 \mathrm{~cm}^{-1}$ using a Shimadzu FTIR-8400s spectrophotometer with a $4 \mathrm{~cm}^{-1}$ resolution over 128 scans. Raman spectra were recorded from $100 \mathrm{~cm}^{-1}$ to $3500 \mathrm{~cm}^{-1}$, on a Jobin Yvon Horiba high-resolution LabRam 800 Raman microscope system, which contains an optical microscope adapted to a double grating spectrograph and a CCD array detector. The laser excitation was provided by a Spectra-Physics model 127 helium-neon laser operating at $35 \mathrm{~mW}$ of $633 \mathrm{~nm}$ output. All the samples for FTIR and Raman experiments were cured in a DSC cell in $\mathrm{N}_{2}$ atmosphere $(60 \mathrm{ml} / \mathrm{min})$. To determine whether the clays were fully exfoliated in the CY matrix, X-ray diffraction (XRD) patterns of the CY/clay nanocomposites were obtained by using a Philip-X9 Pert X-ray diffractometer (anode $40 \mathrm{kV}$, filament current $35 \mathrm{~mA}$ ) with nickel-filtered $\mathrm{CuKa}(\lambda=0.1542 \mathrm{~nm})$ radiation at a scan speed of $1^{\circ} / \mathrm{min}$. To observe the dispersion of the nanofillers in the CY matrix, scanning electron microscopy (SEM) images of 
the fracture surface of the CY/ POSS nanocomposites were taken by field emission gun scanning electron microscopy (FEGSEM) (LEO 1530VP instrument). The samples were fractured at room temperature. The samples with fractured surface on the top were placed on specimen holder using double-sided carbon conductive tap. Gold coating was applied for better conductivity. Transmission electron microscopy (TEM) was employed to observe the state of the nanofillers in the CY matrix as well, using a JEOL 2100 FX instrument. The CY based nanocomposites were cut into the ultra-thin films using a microtome, and then were dropped on a copper grid for direct TEM imaging. Thermogravimertic Analysis (TGA) was performed on a DSC-TGA 2950 instrument. The samples were heated from room temperature to $1000^{\circ} \mathrm{C}$ at a heating rate of $10^{\circ} \mathrm{C} / \mathrm{min}$. The rate of gas (air or nitrogen) was $60 \mathrm{ml} / \mathrm{min}$.

\section{Results and discussion}

\section{Dispersion of the nanofillers in the BEN based nanocomposites}

Figure 1 shows the TEM and SEM images of the cured BEN based nanocomposites. The POSS was dispersed well in the BEN matrix (Figure 1 (A)). For the $1 \mathrm{wt} \%$ POSS/BEN nanocomposite, most of the POSS dispersed in the state of single particle sizing about 3nm, with some aggregates with sizes up to $50 \mathrm{~nm}$ observed. Furthermore, the size of aggregates increased with the increasing concentration, with up to $200 \mathrm{~nm}$ observed in the $10 \mathrm{wt} \%$ POSS/BEN nanocomposite. As shown in Figure 1 (B, C \& D), the $\mathrm{Na}^{+}$clay, the 30B clay, and the 20A clay layers were exfoliated in the BEN matrix. Figure 1 (E, F, G, \& H) shows SEM images of the various BEN/CNT nanocomposites (all at $2 \mathrm{wt} \%$ ). All the functionalised MWCNTs were well dispersed at a nano-scale level in the BEN matrix, with no indication of aggregation taking place. However, for the pure MWCNT/BEN nanocomposite, and the SWCNT-OH/BEN nanocomposite, the CNT bundles were visible at the micro-scale. 

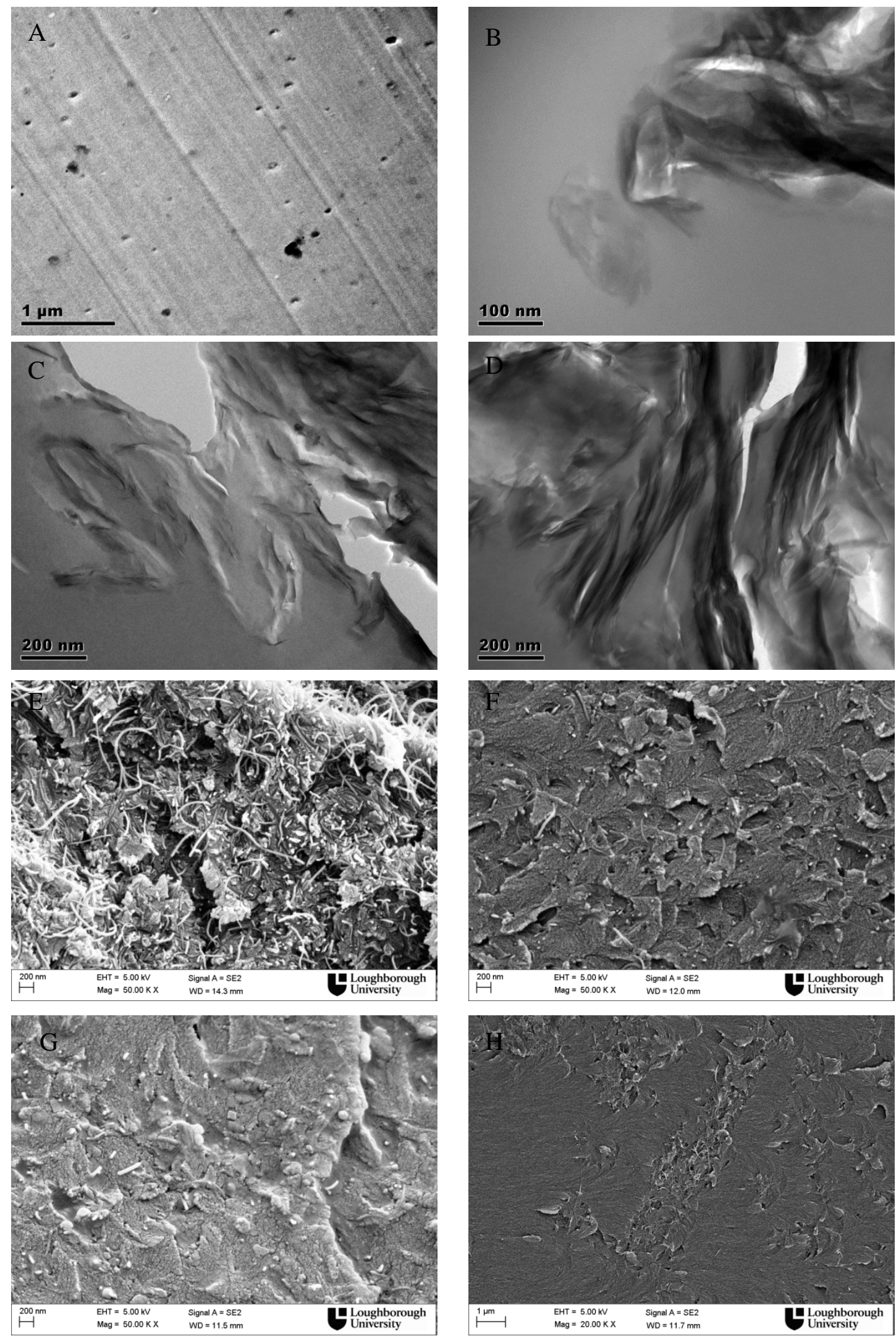

Figure 1: TEM images of the nanocomposites of the BEN incorporated with $5 \mathrm{wt} \%$ POSS(A), 5wt\% Na ${ }^{+} / \mathrm{BEN}$ (B), $1 \mathrm{wt} \%$ 30B/BEN (C), $1 \mathrm{wt} \%$ 20A/BEN (D), $2 \mathrm{wt} \%$ MWCNT/BEN (E), 2 wt\% MWCNT-OH (F), 2 wt\% MWCNT-COOH (G), and 2 wt\% SWCNT-OH (H). 
To further examine the state of clay layers for the different clays in the BEN matrix, the d-spacing of $\mathrm{Na}^{+}$clay, 30B clay, 20A clay, 3 wt\% BEN/ $\mathrm{Na}^{+}$nanocomposite and 3 wt\% BEN/30B nanocomposite, and 3 wt\% BEN/20A nanocomposite were measured using XRD and the results are shown in Figure 2. The original d-spacing of the clays for $\mathrm{Na}^{+}, 30 \mathrm{~B}$, and $20 \mathrm{~A}$ were $1.17 \mathrm{~nm}, 1.85 \mathrm{~nm}$ and $2.42 \mathrm{~nm}$, respectively. For all the nanocomposites, it was noted that there was no peak in the range of $1^{\circ}$ to $10^{\circ}$. This result indicated the exfoliation of the clays in the BEN matrix.
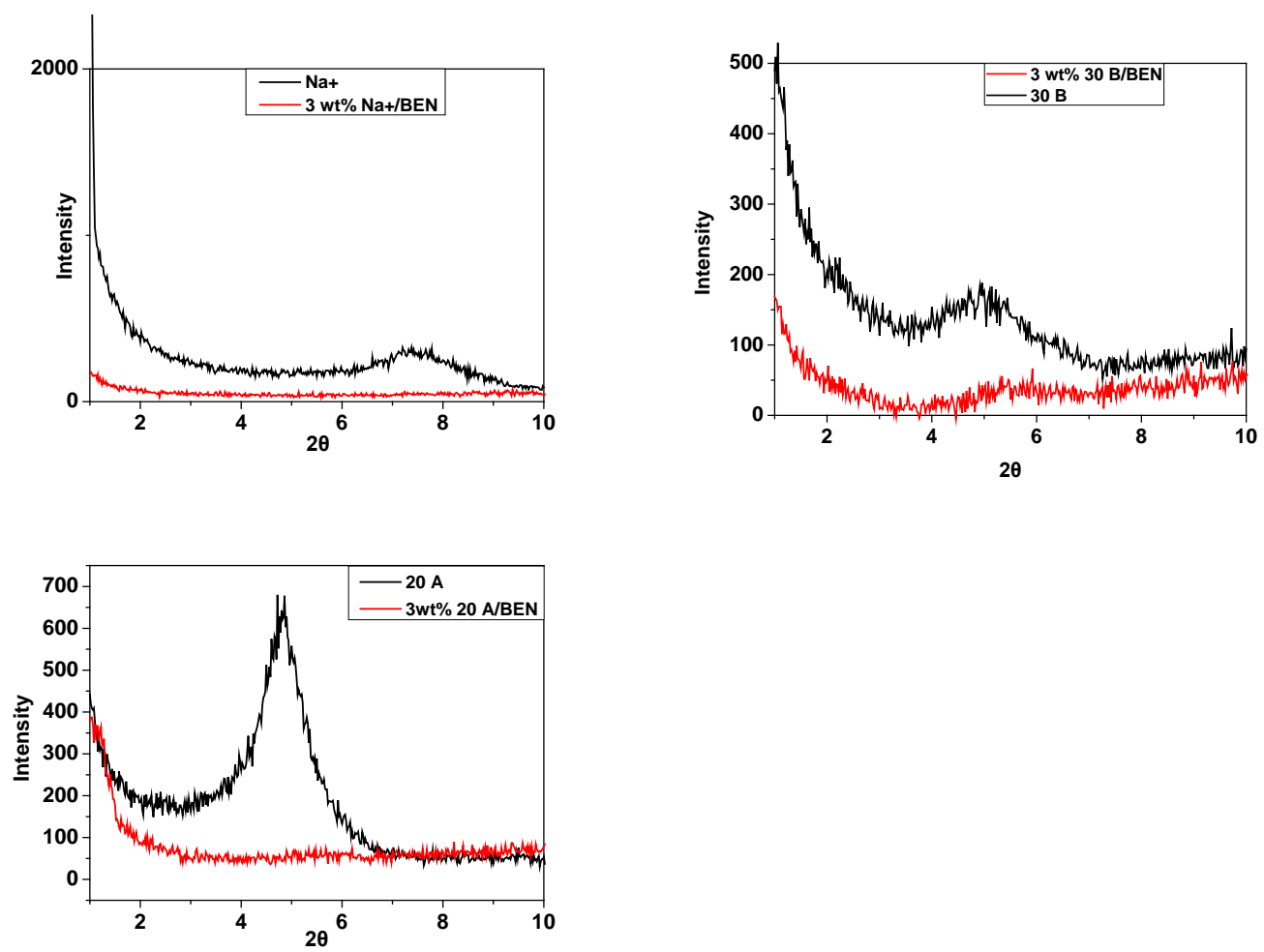

Figure 2: XRD patterns for $\mathrm{Na}^{+}$clay, 30B clay, 20A clay and their BEN/clay nanocomposites.

\section{Curing dynamic of benzoxazine and its nanocomposites}

Figure 3 shows DSC plots of BEN and its nanocomposites in nitrogen atmosphere. Table 1 lists the parameters obtained from DSC experiments. It is clearly that the addition of POSS did not show any catalytic effect. For the clay/BEN nanocomposites, the incorporation of the clays delayed the curing reaction, indicating as the increase of 
peak temperature by up to $5{ }^{\circ} \mathrm{C}$. It is interested that the incorporation of MWCNTs showed good catalytic effect. For 2 wt $\%$ MWCNT-OH, the peak temperature decreased by $27{ }^{\circ} \mathrm{C}$. Furthermore, the reaction enthalpy of 5 wt\% POSS-OH/BEN system was $173 \mathrm{~J} / \mathrm{g}$, significantly lower than that of pure BEN which is $354 \mathrm{~J} / \mathrm{g}$. This observation indicates that the incorporation of POSS-OH hindered the network formation of the BEN.

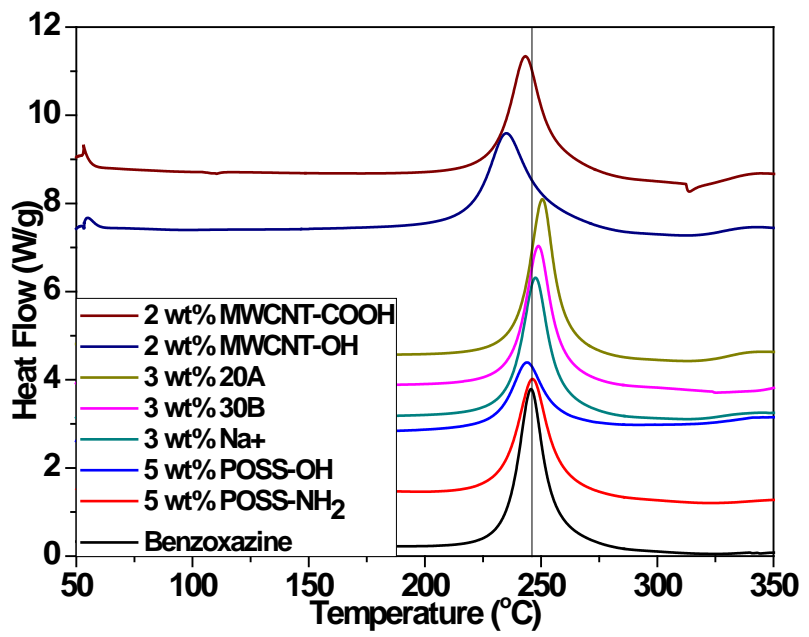

Figure 3: DSC plots of benzoxazine and its nanocomposites in nitrogen atmosphere (60 $\mathrm{ml} / \mathrm{min}$ ) with heating rate of $10^{\circ} \mathrm{C} / \mathrm{min}$.

Table 1: Onset, peak and end temperatures, and enthalpy of the non-isothermal cure of the BEN with different nanofillers

\begin{tabular}{|c|c|c|c|c|c|}
\hline nanofillers & $\begin{array}{l}\text { Onset } \\
\text { Temperature } \\
\left({ }^{\circ} \mathrm{C}\right)\end{array}$ & $\begin{array}{l}\text { Peak } \\
\text { Temperature } \\
\left({ }^{\circ} \mathrm{C}\right)\end{array}$ & $\begin{array}{l}\text { End } \\
\text { temperature } \\
\left({ }^{\circ} \mathrm{C}\right)\end{array}$ & $\begin{array}{l}\text { Duration } \\
\text { (min) }\end{array}$ & $\begin{array}{l}\Delta \mathrm{H} \\
(\mathrm{J} / \mathrm{g})\end{array}$ \\
\hline Neat BEN & 210 & 246 & 288 & 7.8 & 354 \\
\hline $5 \mathrm{wt} \%$ POSS-OH & 206 & 244 & 284 & 7.8 & 173 \\
\hline $5 \mathrm{wt} \%$ POSS-NH & 209 & 246 & 291 & 8.2 & 304 \\
\hline $3 \mathrm{wt} \% \mathrm{Na}^{+}$ & 207 & 248 & 292 & 8.5 & 325 \\
\hline $3 \mathrm{wt} \%$ 30B & 207 & 249 & 288 & 8.1 & 317 \\
\hline $3 \mathrm{wt} \% 20 \mathrm{~A}$ & 209 & 251 & 290 & 8.1 & 345 \\
\hline $\begin{array}{l}2 \mathrm{wt} \% \\
\text { MWCNT-OH }\end{array}$ & 185 & 219 & 294 & 10.9 & 351 \\
\hline $\begin{array}{l}2 \mathrm{wt} \% \\
\text { MWCNT-COOH }\end{array}$ & 201 & 243 & 291 & 9.0 & 342 \\
\hline
\end{tabular}


To further examine the influence of the nanofillers on the curing dynamics of the BEN, the activation energies of the BEN and its nanocomposites during the cure were calculated based on an empirical rate equation proposed by Kamal. ${ }^{19-21}$

Figure 4 shows the plots of heat flow versus curing time for BEN/nanofiller systems at different curing temperatures. Figure 5 shows the plots of conversion rate $(\alpha)$ versus curing time for BEN/nanofiller systems at different curing temperatures. Table 2 summaries the kinetic parameters calculated from the isothermal MDSC experiments using Kamal's equation, for the BEN and its nanocomposites.
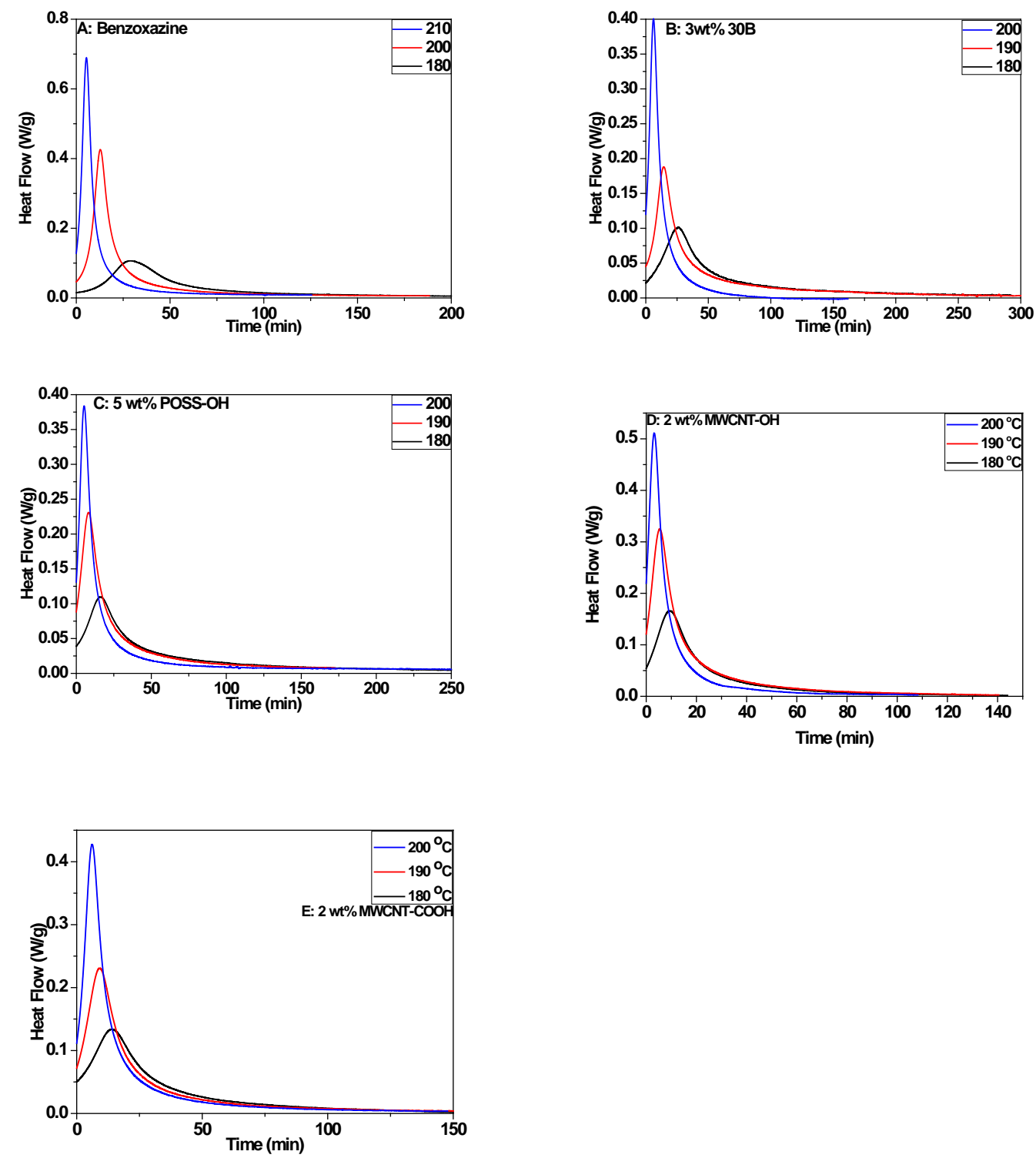

Figure 4: Plots of heat flow versus curing time for BEN/nanofiller systems at different curing temperatures 

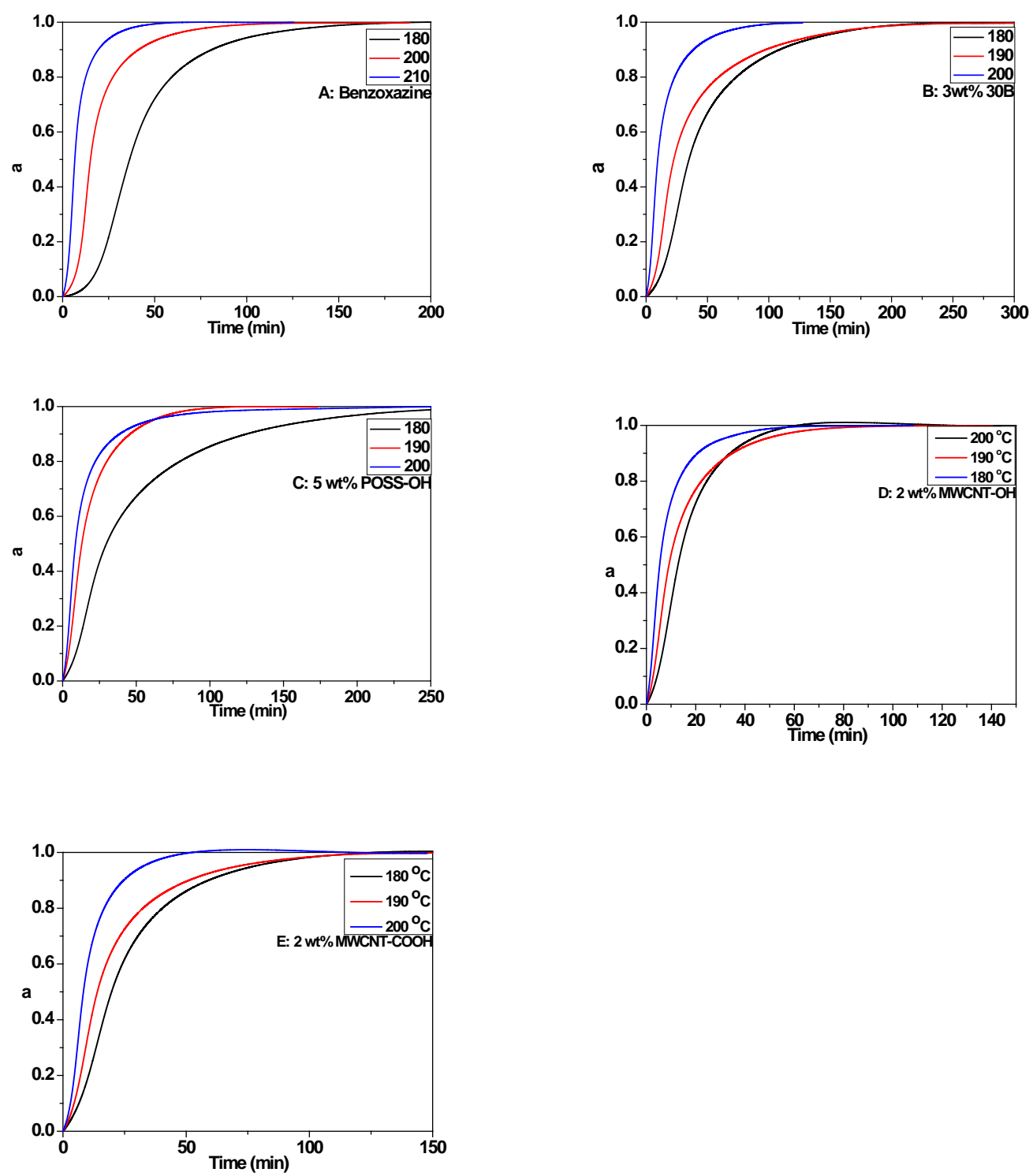

Figure 5: Plots of conversion rate $(\alpha)$ versus curing time for BEN/nanofiller systems at different curing temperatures 
Table 2: Autocatalytic model constants for the BEN and its nanocomposites

\begin{tabular}{|c|c|c|c|c|c|c|c|c|c|}
\hline Sample & $\begin{array}{l}\text { Temperature } \\
\left({ }^{\circ} \mathrm{C}\right)\end{array}$ & $\begin{array}{l}\mathrm{k}_{1} \\
\left(\times 10^{4}\right. \\
\left.\mathrm{s}^{-1}\right) \\
\end{array}$ & $\begin{array}{l}\mathrm{k}_{2} \\
\left(\times 10^{4}\right. \\
\left.\mathrm{s}^{-1}\right) \\
\end{array}$ & $\mathrm{m}$ & $\mathrm{n}$ & $\ln \mathrm{A}_{1}$ & $\ln A_{2}$ & $\begin{array}{l}\mathrm{E}_{1} \\
(\mathrm{~kJ} / \mathrm{mol})\end{array}$ & $\mathrm{E}_{2}(\mathrm{~kJ} / \mathrm{mol})$ \\
\hline \multirow{3}{*}{ BEN } & 180 & 0.08 & 24.2 & 0.928 & 1.77 & \multirow{3}{*}{48} & \multirow{3}{*}{38} & \multirow{3}{*}{229} & \multirow{3}{*}{132} \\
\hline & 200 & 0.979 & 154.6 & 1.469 & 2.629 & & & & \\
\hline & 210 & 3.57 & 192.1 & 1.3 & 2.2685 & & & & \\
\hline \multirow{3}{*}{3 wt\% 30B } & 180 & 0.484 & 24.5 & 1.03 & 2.19 & \multirow{3}{*}{34} & \multirow{3}{*}{24} & \multirow{3}{*}{165} & \multirow{3}{*}{113} \\
\hline & 190 & 0.843 & 47.8 & 1.08 & 2.76 & & & & \\
\hline & 200 & 3.11 & 87 & 1.07 & 2.42 & & & & \\
\hline \multirow{3}{*}{$\begin{array}{l}5 \mathrm{wt} \% \\
\text { POSS-OH }\end{array}$} & 180 & 0.7276 & 18.7 & 0.79 & 2.33 & \multirow{3}{*}{28} & \multirow{3}{*}{29} & \multirow{3}{*}{142} & \multirow{3}{*}{132} \\
\hline & 190 & 2.22 & 40 & 0.876 & 2.01 & & & & \\
\hline & 200 & 3.56 & 82.3 & 0.99 & 2.39 & & & & \\
\hline \multirow{3}{*}{$\begin{array}{l}2 \mathrm{wt} \% \\
\text { MWCNT-OH }\end{array}$} & 180 & 2.23 & 36.1 & 0.86 & 1.549 & \multirow{3}{*}{18} & \multirow{3}{*}{17} & \multirow{3}{*}{100} & \multirow{3}{*}{84} \\
\hline & 190 & 3.09 & 55 & 0.83 & 2.088 & & & & \\
\hline & 200 & 6.89 & 92.7 & 0.90 & 2.06 & & & & \\
\hline \multirow{3}{*}{$\begin{array}{l}2 \mathrm{wt} \% \\
\text { MWCNT-COOH }\end{array}$} & 180 & 1.56 & 31.8 & 1.02 & 1.928 & \multirow{3}{*}{34} & \multirow{3}{*}{24} & \multirow{3}{*}{56} & \multirow{3}{*}{94} \\
\hline & 190 & 2.01 & 48.2 & 0.98 & 2.201 & & & & \\
\hline & 200 & 2.93 & 91.9 & 1.06 & 2.036 & & & & \\
\hline
\end{tabular}

Table 3 shows the kinetic activation energy and the pre-exponential factor for the BEN and its nanocomposites. Figure 6 shows the kinetic activation energy versus conversion for the BEN and its nanocomposites. With the incorporation of the POSS-OH, the activation energy is lower than that of the pure BEN at the very beginning of the cure. However, with the proceeding of the cure, the activation energy increased and exceeded that of pure BEN after conversion of 0.1. This observation implies that the incorporation of POSS-OH hindered the network formation of the BEN, which is accordance with the dynamic DSC result. With the incorporation of the 30B clay, the activation energy is lower than that of the pure BEN at the very beginning and after middle of the cure process, but became higher at the conversion of 0.1 to 0.4 . Thus, considering over all cure process, there is no obvious acceleration effect shown. On the other hand, the incorporation of the functionalised MWCNTs displayed good acceleration effects, the activation energy dropped dramatically at the very beginning, and was lower than that of neat BEN throughout the whole curing process. The results are accordance with the dynamic DSC result. 
Table 3: the kinetic activation energy and the pre-exponential factor for the BEN and its nanocomposites

\begin{tabular}{|c|c|c|c|c|c|c|c|c|c|c|c|c|}
\hline Sample & $\mathrm{a}$ & 0 & 0.1 & 0.2 & 0.3 & 0.4 & 0.5 & 0.6 & 0.7 & 0.8 & 0.9 & 1 \\
\hline \multirow[t]{2}{*}{ BEN } & $\begin{array}{l}\mathrm{E} \\
(\mathrm{kJ} / \mathrm{mol})\end{array}$ & 229 & 87 & 96 & 104 & 110 & 116 & 120 & 124 & 127 & 130 & 133 \\
\hline & $\operatorname{Ln} \mathrm{A}$ & 49 & 15 & 18 & 21 & 22 & 24 & 25 & 27 & 28 & 28 & 29 \\
\hline \multirow[t]{2}{*}{$3 \mathrm{wt} \%$ 30B } & $\begin{array}{l}\mathrm{E} \\
(\mathrm{kJ} / \mathrm{mol})\end{array}$ & 165 & 119 & 115 & 114 & 113 & 113 & 114 & 114 & 114 & 114 & 114 \\
\hline & $\operatorname{Ln} \mathrm{A}$ & 34 & 23 & 23 & 23 & 23 & 23 & 24 & 24 & 24 & 24 & 24 \\
\hline \multirow[t]{2}{*}{5 wt\% POSS-OH } & $\begin{array}{l}\mathrm{E} \\
(\mathrm{kJ} / \mathrm{mol}) \\
\end{array}$ & 142 & 103 & 109 & 114 & 118 & 121 & 124 & 127 & 129 & 131 & 132 \\
\hline & $\operatorname{Ln} \mathrm{A}$ & 28 & 20 & 22 & 23 & 24 & 25 & 26 & 27 & 28 & 28 & 29 \\
\hline \multirow{2}{*}{$\begin{array}{l}2 \mathrm{wt} \% \\
\text { MWCNT-OH }\end{array}$} & $\begin{array}{l}\mathrm{E} \\
(\mathrm{kJ} / \mathrm{mol}) \\
\end{array}$ & 100 & 84 & 83 & 83 & 83 & 84 & 84 & 84 & 84 & 85 & 85 \\
\hline & $\operatorname{Ln} \mathrm{A}$ & 18 & 15 & 15 & 16 & 16 & 16 & 16 & 16 & 17 & 17 & 17 \\
\hline \multirow{2}{*}{$\begin{array}{l}2 \mathrm{wt} \% \\
\text { MWCNT-COOH }\end{array}$} & $\begin{array}{l}\mathrm{E} \\
(\mathrm{kJ} / \mathrm{mol})\end{array}$ & 56 & 78 & 84 & 86 & 88 & 90 & 90 & 91 & 92 & 92 & 93 \\
\hline & $\operatorname{Ln} \mathrm{A}$ & 6 & 13 & 15 & 16 & 17 & 17 & 18 & 18 & 18 & 19 & 19 \\
\hline
\end{tabular}

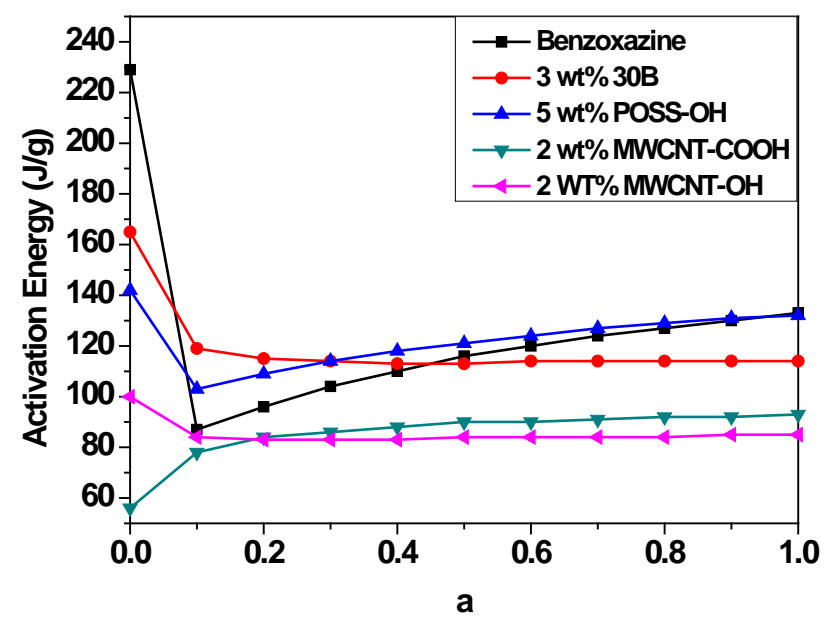

Figure 6: kinetic activation energy versus conversion for the BEN and its nanocomposites.

\subsection{Network formation of benzoxazine and its nanocomposites.}

Figure 7 (A \& B) shows the FTIR spectra for the pure BEN resin cured at $180{ }^{\circ} \mathrm{C}$ in nitrogen atmosphere $(60 \mathrm{ml} / \mathrm{min})$. The characteristic absorption bands of the BEN 
structure were observed at $1600 \mathrm{~cm}^{-1}, 1493 \mathrm{~cm}^{-1}, 1230 \mathrm{~cm}^{-1}$, and $934 \mathrm{~cm}^{-1}$, due to stretching of $\mathrm{C}-\mathrm{N}-\mathrm{O}$ group in oxazine ring, stretching of $\mathrm{C}=\mathrm{C}$ bond in benzene ring, the asymmetric stretching of cyclic $\mathrm{C}-\mathrm{O}-\mathrm{C}$ ether group in oxazine ring, and the stretching of oxazine ring itself, respectively. The cure of the BEN resin can be followed by monitoring the corresponding absence in the absorbance bands of oxazine ring at $1600 \mathrm{~cm}^{-1}, 1230 \mathrm{~cm}^{-1}$, and $934 \mathrm{~cm}^{-1}$. With increased curing time, the absorbance bands of oxazine ring disappeared due to the open of the ring. Another new band at $858 \mathrm{~cm}^{-1}$ assigning to $\mathrm{N}-\mathrm{H}$ wagging and twisting, indicated the occurrence of the ring opening as well. The characteristic band of trisubstituted benzene ring at $1493 \mathrm{~cm}^{-1}$ shifted to $1573 \mathrm{~cm}^{-1}$, which indicated the tetrasubstitution of the benzene ring. Furthermore, a new band at $1173 \mathrm{~cm}^{-1}$ assigned to C-O stretching of phenol groups, indicated the formation of the phenol structure. The presence of absorbance bands at $1573 \mathrm{~cm}^{-1}$ and $1620 \mathrm{~cm}^{-1}$ indicating the C-N stretching and aromatic $\mathrm{C}=\mathrm{O}$ stretching, also provided evidence of the oxazine ring opening and cure. It should be noticed here that the intensity of the absorbance bands of oxazine ring remained the same until 40 mintues, and then the absorbance bands suddenly disappeared or decreased. Furthermore, the intensity of the new bands changed little with the curing time. This observation reflects the fact that the opening of the oxazine ring and the formation of benoxazine network is completed in a short period, rather than gradually or step by step formation of the network which happened during the cure of cyanate ester. Figure 7 (C) shows the FTIR spectra for the BEN/30B clay resin cured at $180{ }^{\circ} \mathrm{C}$ in nitrogen atmosphere $(60 \mathrm{ml} / \mathrm{min})$. The characteristic bands at 1076 $\mathrm{cm}^{-1}$ and $998 \mathrm{~cm}^{-1}$ assigned to Si-O-C stretching and Si-O-Si asymmetric stretching respectively, indicated the presence of the $30 \mathrm{~B}$ clay. The procedure for monitoring the cure of the BEN/clay resin is the same as that of pure BEN resin. For the BEN/clay system, all the bands changed after 20 minutes, more quickly than that of the pure BEN system which changed after 40 minutes. Thus, it is clear that the incorporation of the clay accelerated the cure process of the BEN. Apart from the bands present in the FTIR spectra of the cure of BEN, a new broad band is observed at $1027 \mathrm{~cm}^{-1}$ assigned to stretching of the ether $\mathrm{C}-\mathrm{O}-\mathrm{C}$ group. This observation indicated the 
reaction of the clay with the BEN during the cure. The FTIR spectra of the cure of 5 wt\% POSS/BEN nanocomposite with time are given in Figure 7 (D). The procedure for monitoring the cure of the BEN/POSS nanocomposite is the same as that of pure BEN resin. There was no accelerating effect with the addition of the POSS. The POSS reacted with the BEN during the cure, proved by the presence of the band at 1050 $\mathrm{cm}^{-1}$, indicating the formation of Si-O-C bond. Figure 7 (E) shows the FTIR spectra for the BEN/MWCNT-COOH resin cured at $180{ }^{\circ} \mathrm{C}$ in nitrogen atmosphere (60ml/min). The characteristic band near $1650 \mathrm{~cm}^{-1}$ is assigned to $\mathrm{C}=\mathrm{O}$ stretching, indicated the presence of the MWCNT-COOH. The procedure for monitoring the cure of the BEN/MWCNT-COOH resin is the same as that of pure BEN resin. For the BEN/MWCNT system, the addition of the CNT accelerated the cure process of the BEN. All the bands changed after 20 minutes, more quickkly than for the pure BEN system which changed after 40 minutes. Apart from the bands present in the FTIR spectra of the cure of BEN, two new bands are observed at $1250 \mathrm{~cm}^{-1}$ and $1750 \mathrm{~cm}^{-1}$ assigned to stretching of the $\mathrm{C}-\mathrm{O}$ bond and $\mathrm{C}=\mathrm{O}$ bond, respectively. These two bands indicated the reaction of the MWCNT-COOH with the BEN to form an ester group. The scheme of the reaction of the nanofillers with BEN is shown in Figure 8. 

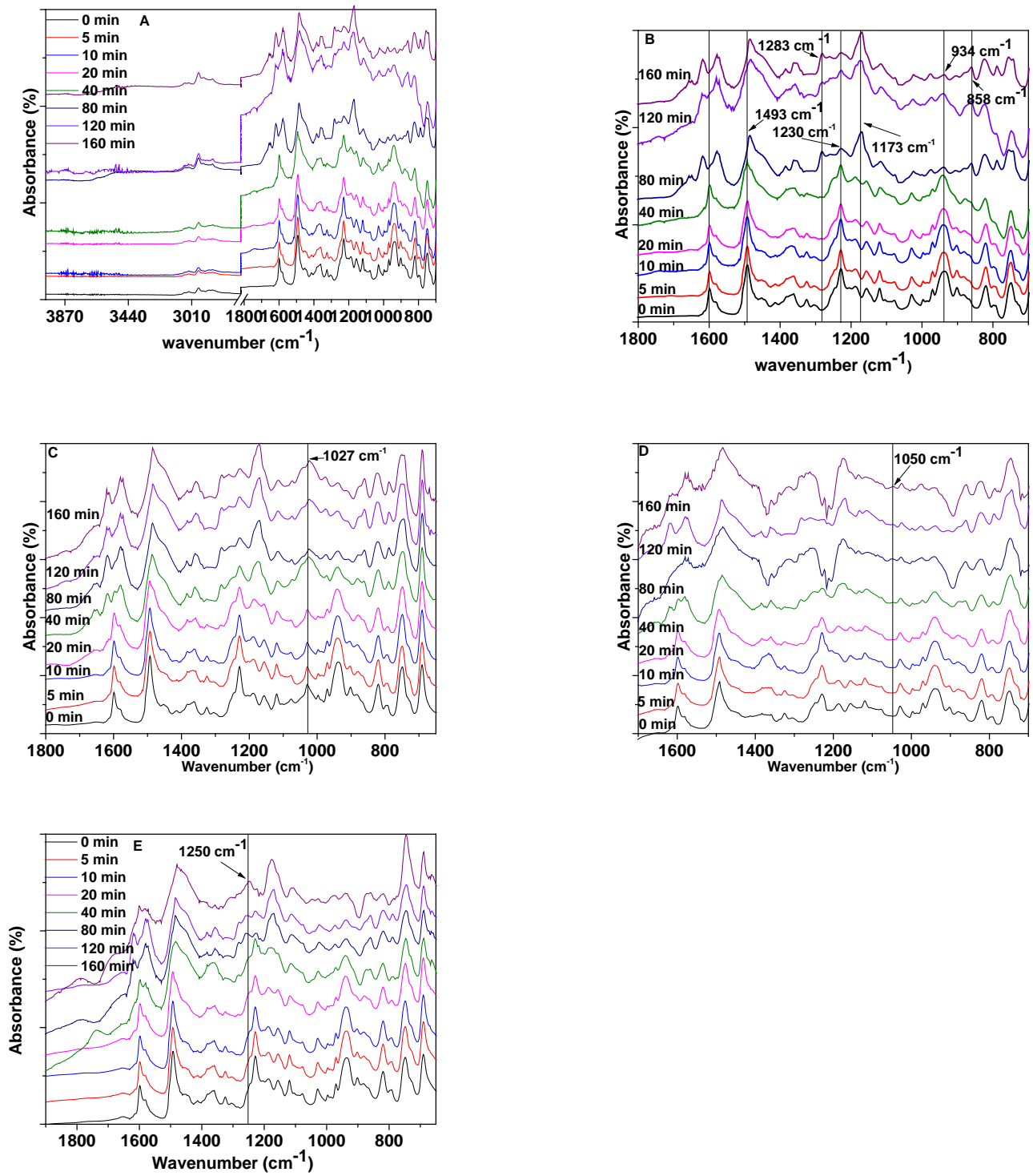

Figure 7: FTIR spectra for the pure BEN and its nanocomposites cured at $180{ }^{\circ} \mathrm{C}$ in nitrogen atmosphere $(60 \mathrm{ml} / \mathrm{min})$. (A) original, (B) enlarged $\mathrm{A}$, (C) $3 \mathrm{wt} \%$ 30B/BEN, (D) $5 \mathrm{wt} \%$ POSS-OH/BEN, (E) $2 \mathrm{wt} \%$ MWCNT-COOH. For clarification, the spectra were shift parallel, and were calibrated basing the absorption band of phenyl ring symmetric breathing vibration near $1500 \mathrm{~cm}^{-1}$. 
Table 4: Analytical results of the FTIR spectra of the pure BEN resin cured at $180{ }^{\circ} \mathrm{C}$

\begin{tabular}{|l|l|l|}
\hline Wave number $\left(\mathrm{cm}^{-1}\right)$ & Assignment & Bond \\
\hline 1230 & Asymmetric C-O stretching & Cyclic ether C-O-C \\
\hline 1173 & C-O stretching & Phenol C-OH \\
\hline 3520 & O-H stretching & Phenol C-OH \\
\hline 1493 & C=C stretching & trisubstituted benzene ring \\
\hline 1483 & C=C stretching & tetrasubstituted benzene ring \\
\hline 1600 & Oxazine ring C-N-O stretching & N-C-O \\
\hline 1573 & C-N stretching & C-N-C \\
\hline 1620 & Aromatic C=O stretching & Aromatic C=O \\
\hline 934 & Oxazine ring stretching & Oxazine ring \\
\hline 858 & N-H wagging and weisting & N-H \\
\hline
\end{tabular}
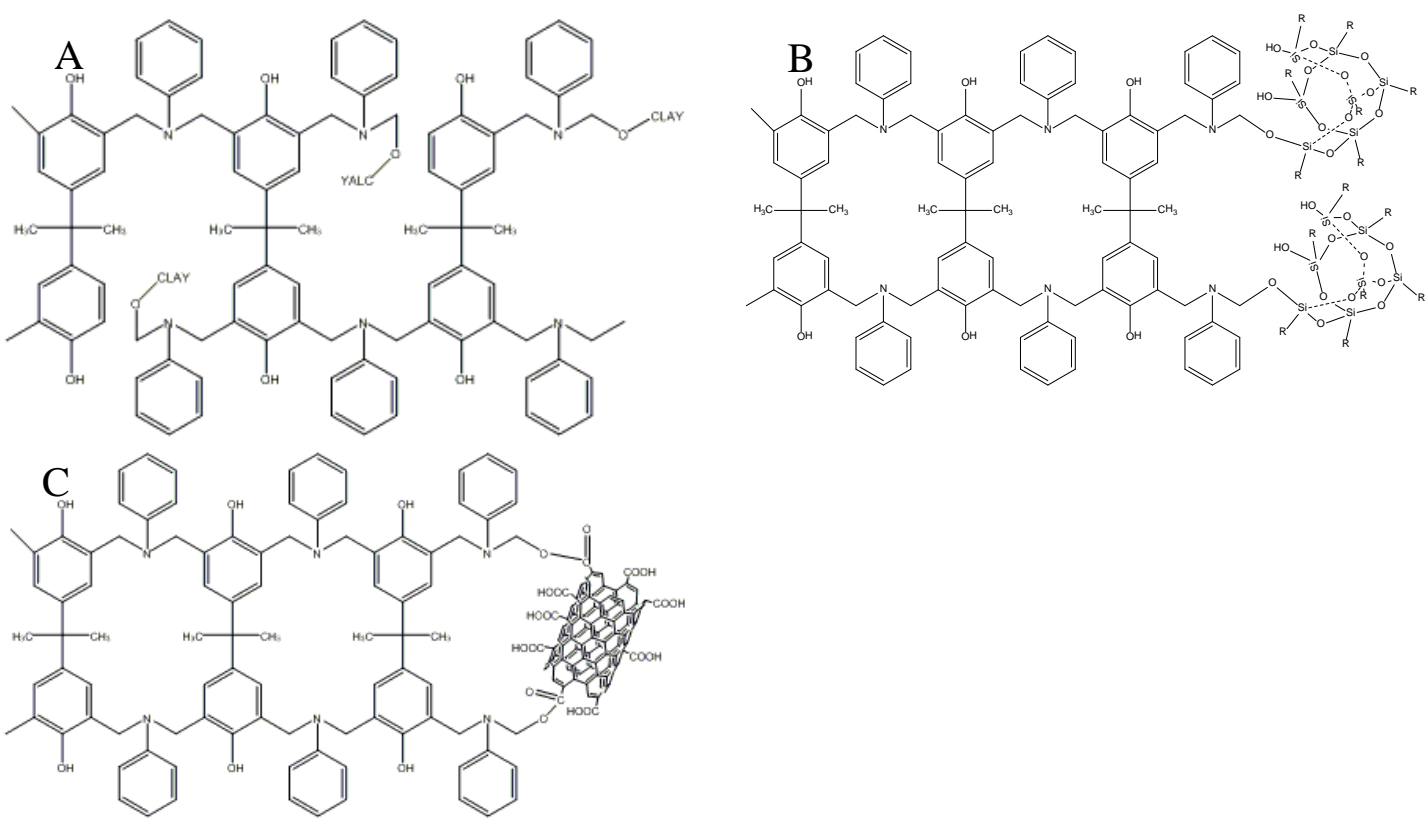

Figure 8: Scheme of crosslinked network formation of the (A) BEN/clay (B) BEN/POSS and (C) BEN/CNT nanocomposites.

\section{TGA analysis}

The thermal stability of the pristine BEN, and its nanocomposites incorporating nanoclay, POSS, and CNT were evaluated by dynamic thermogravimertic analysis (TGA). Figure 9 shows the TGA results of the BEN/clay nanocomposites under air atmosphere. Table 5 lists the experimental indicators for thermal stability from the TGA experiment. Under air atmosphere, the BEN became significantly less stable with the incorporation of $1 \mathrm{wt} \%$ of clays. Nevertheless, the incorporation of the clays 
with higher concentrations showed significant improvement to the thermal stability of BEN. For the 20A/BEN and 30B/BEN nanocomposites, the best performance was observed with the incorporation of the $5 \mathrm{wt} \%$ clays. For the $\mathrm{Na}^{+} / \mathrm{BEN}$ nanocomposite, the best result showed when $3 \mathrm{wt} \% \mathrm{Na}^{+}$was added. In Figure 9 (D), the clays with best performance in each group were compared. There is not any obvious difference between them. The onset temperature increased from $320{ }^{\circ} \mathrm{C}$ to about $350{ }^{\circ} \mathrm{C}$. The half life decomposition temperature also increased by $30{ }^{\circ} \mathrm{C}$. However, there is no improvement in full decomposition temperature with the incorporation of clays.
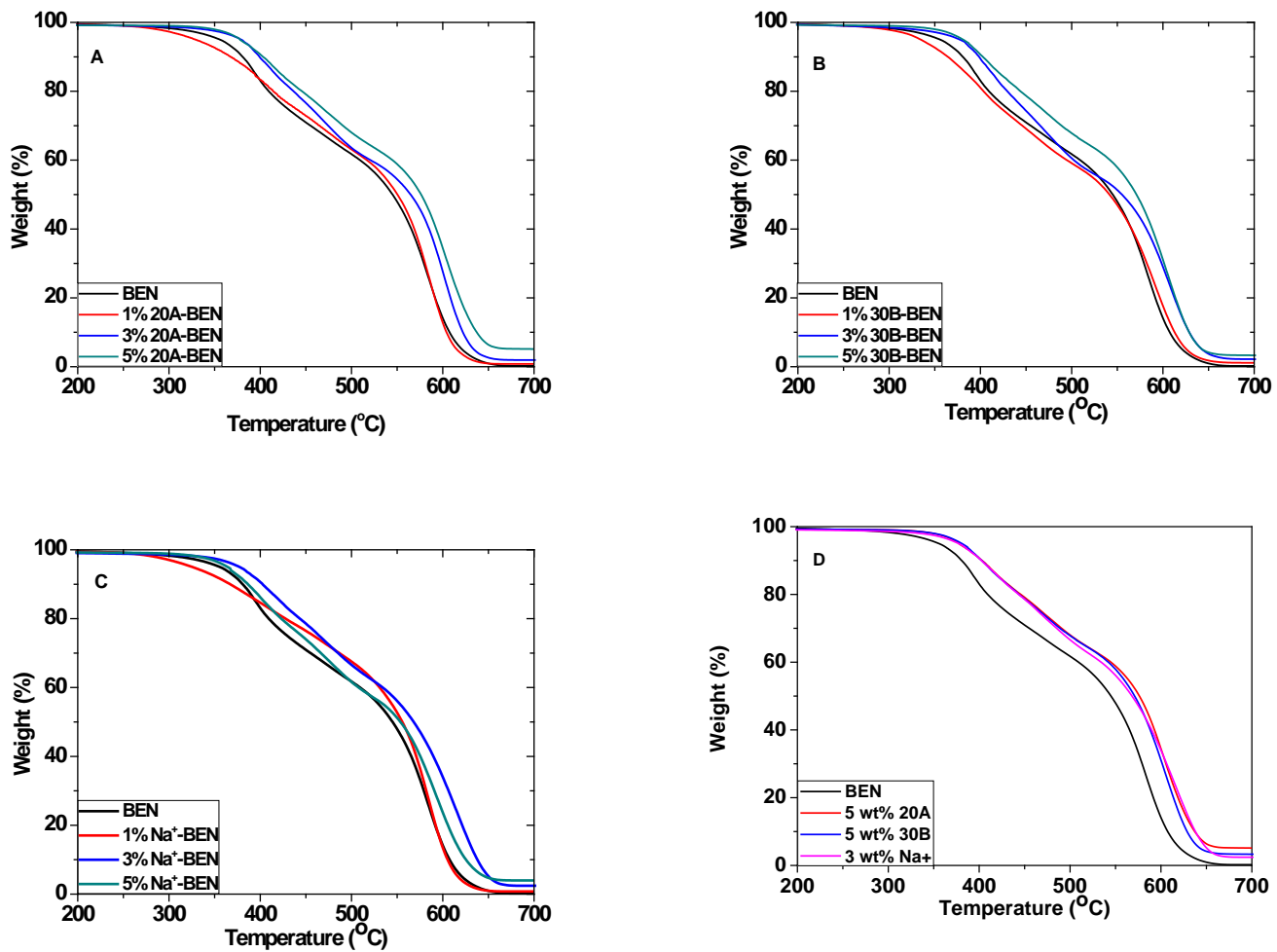

Figure 9: TGA results of BEN/clay nanocomposites with residual weight in percentage vs. temperature (A) 20A/BEN, (B)30B/BEN, (C) $\mathrm{Na}^{+} / \mathrm{BEN}$, and (D) comparative results for the clays performed best in each group. 
Table 5: experimental indicators for thermal stability from the TGA experiment.

\begin{tabular}{|c|c|c|c|c|}
\hline sample & $\mathrm{T}_{\mathrm{o}}$ & $\mathrm{T}_{\mathrm{c}}$ & $\mathrm{T}_{1 / 2}$ & Char yield (\%) \\
\hline Pure BEN & 320 & 660 & 544 & 0 \\
\hline $1 \mathrm{wt} \%$ 20A/BEN & 280 & 644 & 551 & 2 \\
\hline $3 \mathrm{wt} \%$ 20A/BEN & 351 & 660 & 564 & 5 \\
\hline $5 \mathrm{wt} \% 20 \mathrm{~A} / \mathrm{BEN}$ & 351 & 660 & 576 & 1 \\
\hline $1 \mathrm{wt} \% 30 \mathrm{~B} / \mathrm{BEN}$ & 288 & 657 & 540 & 2 \\
\hline $3 \mathrm{wt} \% 30 \mathrm{~B} / \mathrm{BEN}$ & 329 & 664 & 555 & 3 \\
\hline $5 \mathrm{wt} \% 30 \mathrm{~B} / \mathrm{BEN}$ & 353 & 664 & 570 & 1 \\
\hline $1 \mathrm{wt} \% \mathrm{Na}^{+} / \mathrm{BEN}$ & 277 & 647 & 554 & 2 \\
\hline $3 \mathrm{wt} \% \mathrm{Na}^{+} / \mathrm{BEN}$ & 345 & 676 & 568 & 4 \\
\hline $5 \mathrm{wt} \% \mathrm{Na}^{+} / \mathrm{BEN}$ & 345 & 663 & 554 & \\
\hline
\end{tabular}

$\mathrm{T}_{0}$ : onset temperature at which decomposition started.

$\mathrm{T}_{\mathrm{c}}$ : completion temperature at which decomposition finished.

$\mathrm{T}_{1 / 2}$ : half-life decomposition temperature at which $50 \%$ weight loss of the initial weight occurred.

Figure 10 shows the TGA results of the BEN/clay nanocomposites under nitrogen atmosphere. Table 6 lists the experimental indicators for thermal stability from the TGA experiment. Under nitrogen atmosphere, the BEN and its nanocomposites did not fully degrade even at temperatures in excess of $800{ }^{\circ} \mathrm{C}$. Generally, the incorporation of the clays with high concentration (over $1 \mathrm{wt} \%$ ) showed significant improvement to the thermal stability of BEN. For the 20A/BEN nanocomposite and the 30B/BEN nanocomposite, the thermal stability increased with the increasing concentration. The best enhancement was observed with the incorporation of the $5 \mathrm{wt} \%$ clays. For the $\mathrm{Na}^{+} / \mathrm{BEN}$ nanocomposite, the best result showed when $3 \mathrm{wt} \% \mathrm{Na}^{+}$was added. As shown in Figure 10 (D), the clays with best performance in each group were compared. The best enhancement for the thermal stability of the BEN was shown with the incorporation of $5 \mathrm{wt} \%$ 30B clay. The onset temperature was increased by $70{ }^{\circ} \mathrm{C}$. It is remarkable that the half-life decomposition temperature increased from $493{ }^{\circ} \mathrm{C}$ to $729{ }^{\circ} \mathrm{C}$, which is an improvement of $336{ }^{\circ} \mathrm{C}$. Furthermore, the char yield at $800{ }^{\circ} \mathrm{C}$ increased $8 \mathrm{wt} \%$. 

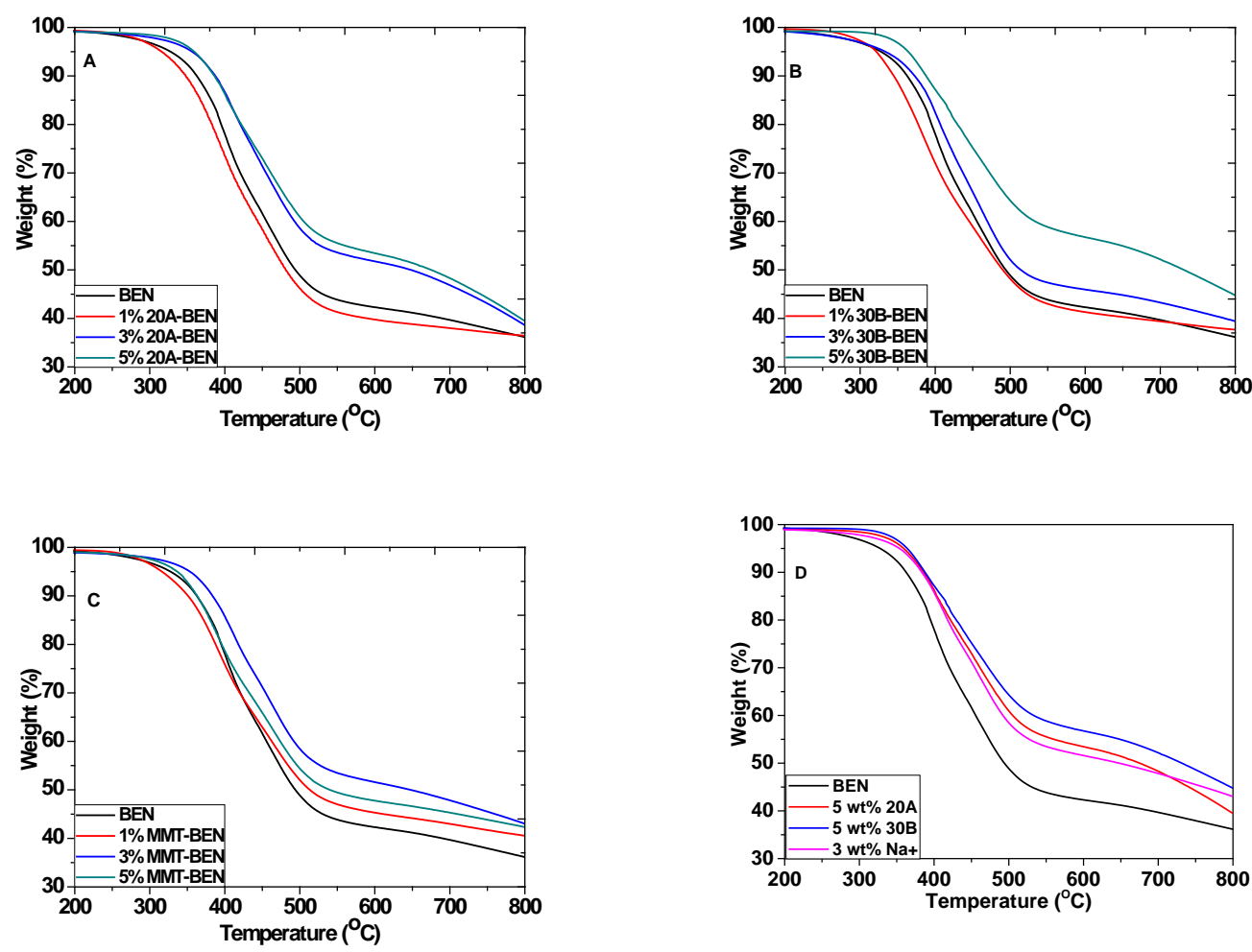

Figure 10: TGA results of BEN/clay nanocomposites with residual weight in percentage vs. temperature (A) 20A/BEN, (B)30B/BEN, (C) $\mathrm{Na}^{+} / \mathrm{BEN}$, and (D) comparative results for the clays performed best in each group.

Table 6: experimental indicators for thermal stability from the TGA experiment.

\begin{tabular}{|c|c|c|c|}
\hline sample & $\mathrm{T}_{0}$ & $\mathrm{~T}_{1 / 2}$ & Char yield at $800{ }^{\circ} \mathrm{C}(\%)$ \\
\hline Pure BEN & 257 & 493 & 36 \\
\hline $1 \mathrm{wt} \%$ 20A/BEN & 257 & 481 & 36 \\
\hline $3 \mathrm{wt} \%$ 20A/BEN & 283 & 640 & 39 \\
\hline $5 \mathrm{wt} \%$ 20A/BEN & 315 & 671 & 40 \\
\hline $1 \mathrm{wt} \%$ 30B/BEN & 282 & 489 & 38 \\
\hline $3 \mathrm{wt} \% 30 \mathrm{~B} / \mathrm{BEN}$ & 253 & 513 & 39 \\
\hline $5 \mathrm{wt} \% 30 \mathrm{~B} / \mathrm{BEN}$ & 328 & 729 & 40 \\
\hline $1 \mathrm{wt} \% \mathrm{Na}^{+} / \mathrm{BEN}$ & 275 & 512 & 43 \\
\hline $3 \mathrm{wt} \% \mathrm{Na}^{+} / \mathrm{BEN}$ & 282 & 538 & 42 \\
\hline $5 \mathrm{wt} \% \mathrm{Na}^{+} / \mathrm{BEN}$ & 289 & 639 & \\
\hline
\end{tabular}

Figure 11 (A) shows the TGA results of the BEN/POSS nanocomposite under air atmosphere. Table 7 lists the experimental indicators for thermal stability from the TGA experiment. Under air atmosphere, the incorporation of the POSS with high 
concentration showed good improvement to the thermal stability of the BEN. With the incorporation of $1 \mathrm{wt} \%$ POSS, the thermal stability of the BEN was slightly impaired at the temperatures lower than $400{ }^{\circ} \mathrm{C}$. and the onset decomposition temperature reduced by $56{ }^{\circ} \mathrm{C}$. When the concentration is higher than $1 \mathrm{wt} \%$, the thermal stability increased with increasing concentration. The best performance was observed with the incorporation of the $10 \mathrm{wt} \%$ POSS. The half-life decomposition temperature was increased by $34{ }^{\circ} \mathrm{C}$. Figure 11 (B) shows the TGA results of the BEN/clay nanocomposites under nitrogen atmosphere. Table 8 lists the experimental indicators for thermal stability from the TGA experiment. Under nitrogen atmosphere, the BEN and its POSS nanocomposites did not fully degrade even if the temperature rose to $800{ }^{\circ} \mathrm{C}$. With the incorporation of $1 \mathrm{wt} \%$ POSS, the BEN was intially less thermally stable and bcame comparatively more stable with increasing temperature. The best performance was observed when 5 wt $\%$ POSS was incorporated. The half-life decomposition temperature and char yield were enhanced by $280{ }^{\circ} \mathrm{C}$ and $13 \mathrm{wt} \%$. The thermal stability of the $10 \mathrm{wt} \%$ BEN/POSS nanocomposite isbetter than that of pure BEN, but not as good as that of $5 \mathrm{wt} \%$ one.

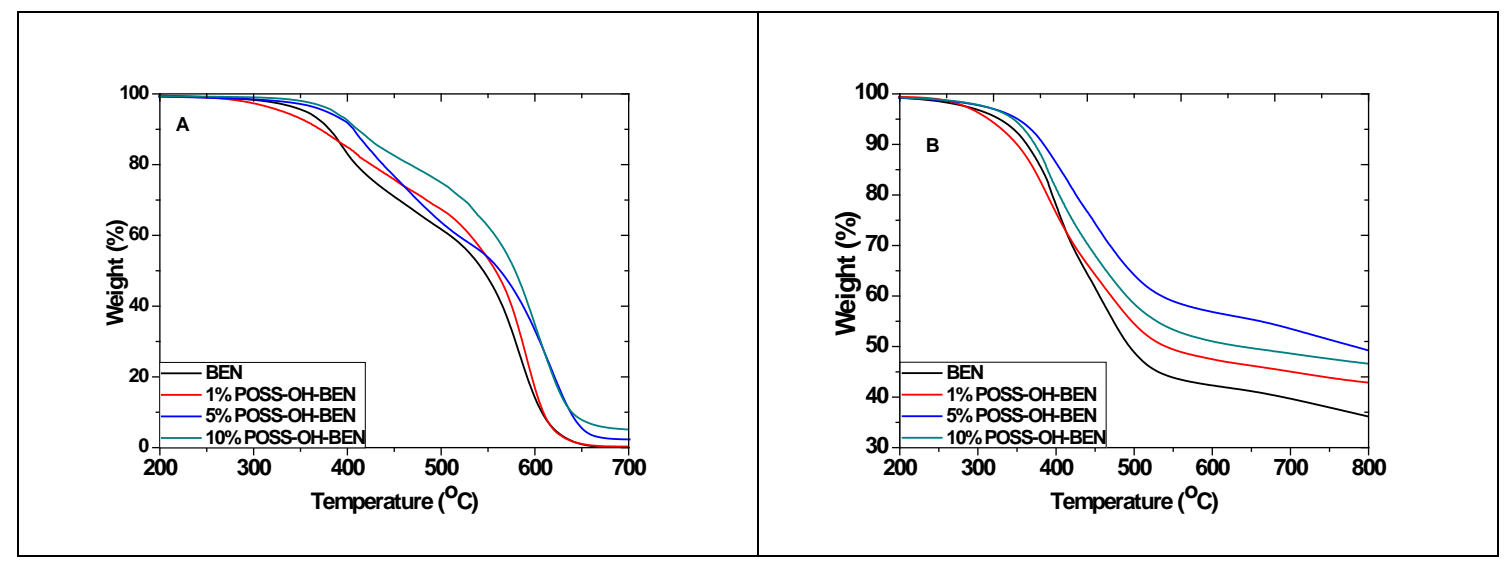

Figure 11: TGA results of BEN/clay nanocomposites with residual weight in percentage vs. temperature (A) under air atmosphere (20 $\mathrm{ml} / \mathrm{min})$, and (B) under nitrogen atmosphere $(20 \mathrm{ml} / \mathrm{min})$, with a heating rate of $10{ }^{\circ} \mathrm{C} / \mathrm{min}$. 
Table 7: Experimental indicators for thermal stability of BEN and its POSS nanocomposite under air atmosphere.

\begin{tabular}{|l|l|l|l|l|}
\hline sample & $\mathrm{T}_{\mathrm{o}}$ & $\mathrm{T}_{\mathrm{c}}$ & $\mathrm{T}_{1 / 2}$ & Char yield (\%) \\
\hline Pure BEN & 320 & 660 & 544 & 0 \\
\hline $1 \mathrm{wt} \%$ POSS/BEN & 264 & 668 & 558 & 0 \\
\hline $5 \mathrm{wt} \%$ POSS/BEN & 278 & 673 & 564 & 3 \\
\hline $10 \mathrm{wt} \%$ POSS/BEN & 338 & 684 & 578 & 5 \\
\hline
\end{tabular}

Table 8: experimental indicators for thermal stability of BEN and its POSS nanocomposite under nitrogen atmosphere

\begin{tabular}{|l|l|l|l|}
\hline sample & $\mathrm{T}_{\mathrm{o}}$ & $\mathrm{T}_{1 / 2}$ & Char yield at $800{ }^{\circ} \mathrm{C}(\%)$ \\
\hline Pure BEN & 257 & 493 & 36 \\
\hline $1 \mathrm{wt} \%$ POSS/BEN & 263 & 537 & 43 \\
\hline $5 \mathrm{wt} \%$ POSS/BEN & 278 & 773 & 49 \\
\hline $10 \mathrm{wt} \%$ POSS/BEN & 278 & 619 & 47 \\
\hline
\end{tabular}

Figure 12 shows the TGA results of the BEN/CNT nanocomposite under air atmosphere. Table 9 lists the experimental indicators for thermal stability from the TGA experiment. In general, the addition of CNT improved the thermal stability of BEN, but the situation is very complex. For the MWCNT/BEN nanocomposites, the incorporation of $1 \mathrm{wt} \%$ MWCNT impaired the thermal stability. For the $2 \mathrm{wt} \%$ and 4 wt\% MWCNT/BEN nanocomposites, the thermal stability was enhanced, with the 2 wt\% MWCNT/BEN nanocomposite performing better below $569{ }^{\circ} \mathrm{C}$. For the MWCNT-OH/BEN nanocomposites, the $1 \mathrm{wt} \%$ and $4 \mathrm{wt} \%$ loaded nanocomposites showed similar enhancement to the thermal stability of BEN. For the MWCNT-COOH/BEN nanocomposites, the $2 \mathrm{wt} \%$ loaded nanocomposite was the most thermally stable below $412{ }^{\circ} \mathrm{C}$, with 1 wt\% MWCNT-COOH/BEN nanocomposite performing best above $412{ }^{\circ} \mathrm{C}$. Furthermore, the thermal stability of 2 wt\% SWCNT-OH/BEN nanocomposite is better than that of pure BEN. It can be seen from Figure 12 (E) that $2 \mathrm{wt} \%$ MWCNT/BEN showed best thermal stability below $566{ }^{\circ} \mathrm{C}$, and $4 \mathrm{wt} \%$ MWCNT/BEN nanocomposite became most thermally stable above $566{ }^{\circ} \mathrm{C}$. With the incorporation of $4 \mathrm{wt} \%$ MWCNT, the half-life decomposition 
temperature was increased by around $40{ }^{\circ} \mathrm{C}$. In conclusion, the pure MWCNT displayed best performance among all of the CNTs.
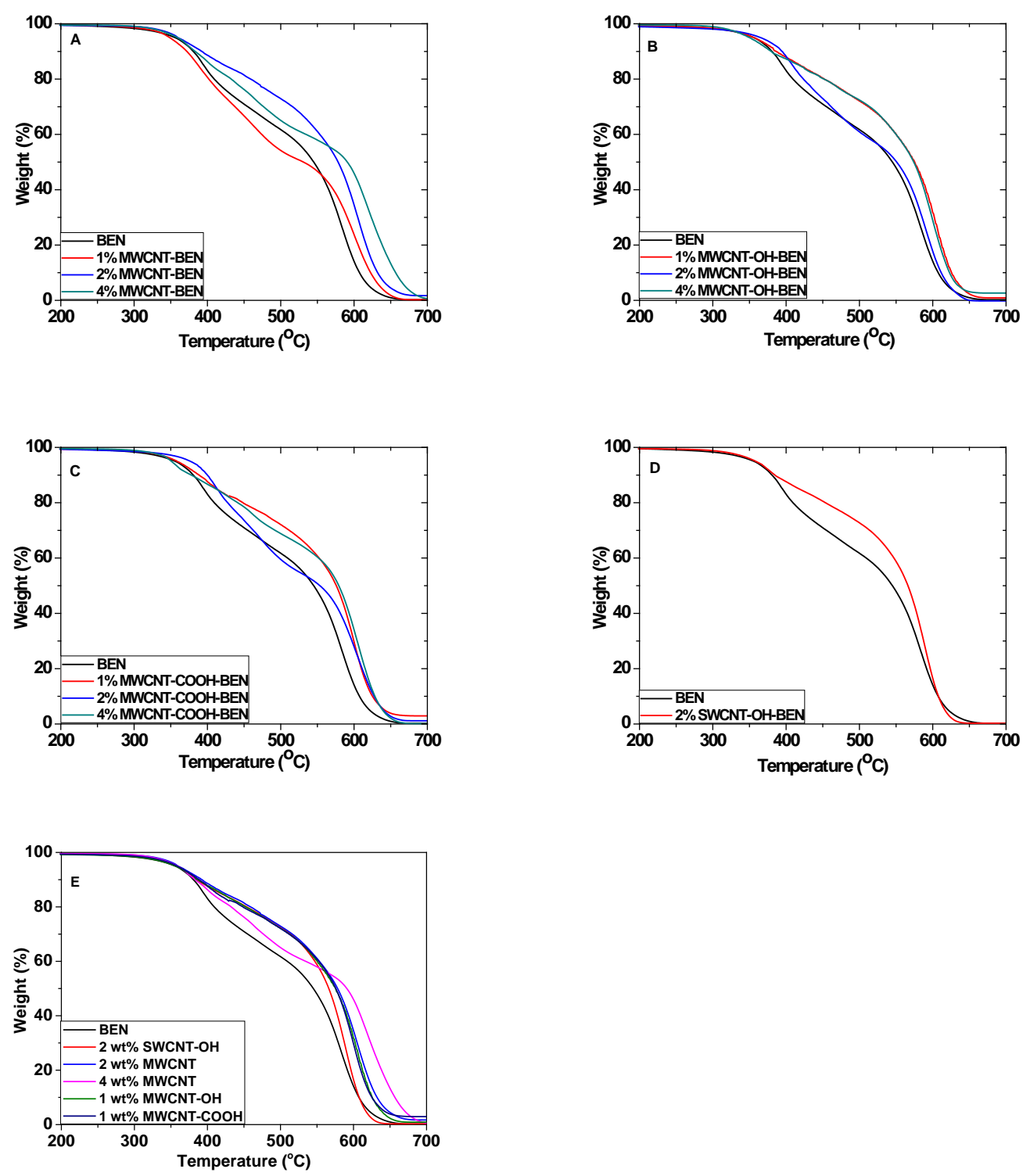

Figure 12: TGA results of BEN/CNT with residual weight in percentage vs. temperature (A) MWCNT/BEN, (B) MWCNT-OH/BEN, (C) MWCNT-COOH/BEN, (D) SWCNT-OH/BEN, and (E) comparative results, with a heating rate of $10{ }^{\circ} \mathrm{C} / \mathrm{min}$ under air atmosphere (20 ml/min). 
Table 9: Experimental indicators for thermal stability from the TGA experiment.

\begin{tabular}{|l|l|l|l|l|}
\hline sample & $\mathrm{T}_{\mathrm{o}}$ & $\mathrm{T}_{\mathrm{c}}$ & $\mathrm{T}_{1 / 2}$ & Char yield (\%) \\
\hline Pure BEN & 320 & 660 & 544 & 0 \\
\hline 1 wt\% MWCNT/BEN & 305 & 665 & 529 & 0 \\
\hline 2 wt\% MWCNT/BEN & 319 & 675 & 577 & 2 \\
\hline $4 \mathrm{wt} \%$ MWCNT/BEN & 319 & 692 & 590 & 1 \\
\hline 1 wt\% MWCNT-OH/BEN & 310 & 662 & 573 & 1 \\
\hline 2 wt\% MWCNT-OH/BEN & 254 & 643 & 550 & 0 \\
\hline 4 wt\% MWCNT-OH/BEN & 311 & 663 & 573 & 4 \\
\hline 1 wt\% MWCNT-COOH/BEN & 317 & 662 & 575 & 3 \\
\hline 2 wt\% MWCNT-COOH/BEN & 310 & 672 & 552 & 1 \\
\hline 4 wt\% MWCNT-COOH/BEN & 316 & 662 & 579 & 0 \\
\hline 2 wt\% SWCNT-OH/BEN & 313 & 640 & 565 & 1 \\
\hline
\end{tabular}

Figure 13 shows the TGA results of the BEN/CNT nanocomposite under nitrogen atmosphere. Table 10 lists the experimental indicators for thermal stability from the TGA experiment. In common with the analysis that under air atmosphere, the addition of CNTs improved the thermal stability of the BEN, but the situation is again very complex. For the MWCNT/BEN nanocomposites, the incorporation of $1 \mathrm{wt} \%$ MWCNT did not show much improvement to the thermal stability. The strongest reinforcement was observed with the incorporation of $4 \mathrm{wt} \%$ MWCNTs. For the MWCNT-OH/BEN nanocomposites, the $1 \mathrm{wt} \%$ and $4 \mathrm{wt} \%$ loaded nanocomposites showed similar enhancement to the thermal stability of the BEN. 2 wt\% MWCNT-OH/BEN nanocomposite performed better below $464{ }^{\circ} \mathrm{C}$. For the MWCNT-COOH/BEN nanocomposites, the 2 wt\% loaded nanocomposite was relatively thermally stable below $425{ }^{\circ} \mathrm{C}$, with 4 wt\% MWCNT-COOH/BEN nanocomposite showing significantly enhancement above $412{ }^{\circ} \mathrm{C}$. Furthermore, the thermal stability of 2 wt\% SWCNT-OH/BEN nanocomposite is better than that of the BEN. It can be shown from Figure 13 (E) that $4 \mathrm{wt} \%$ MWCNT/BEN nanocomposite showed best thermal stability below $465{ }^{\circ} \mathrm{C}$, and $4 \mathrm{wt} \%$ MWCNT-COOH performed best above $465{ }^{\circ} \mathrm{C}$. With the addition of $4 \mathrm{wt} \%$ MWCNT, the onset decomposition of BEN increased by $74{ }^{\circ} \mathrm{C}$. For the 4 wt\% MWCNT-COOH/BEN nanocomposite, the half-life decomposition temperature and char yield at $800{ }^{\circ} \mathrm{C}$ increased by $286{ }^{\circ} \mathrm{C}$ and 
$14 \mathrm{wt} \%$, respectively. In conclusion, the type of CNT and concentration should be carefully chosen to fit typical application temperature range.
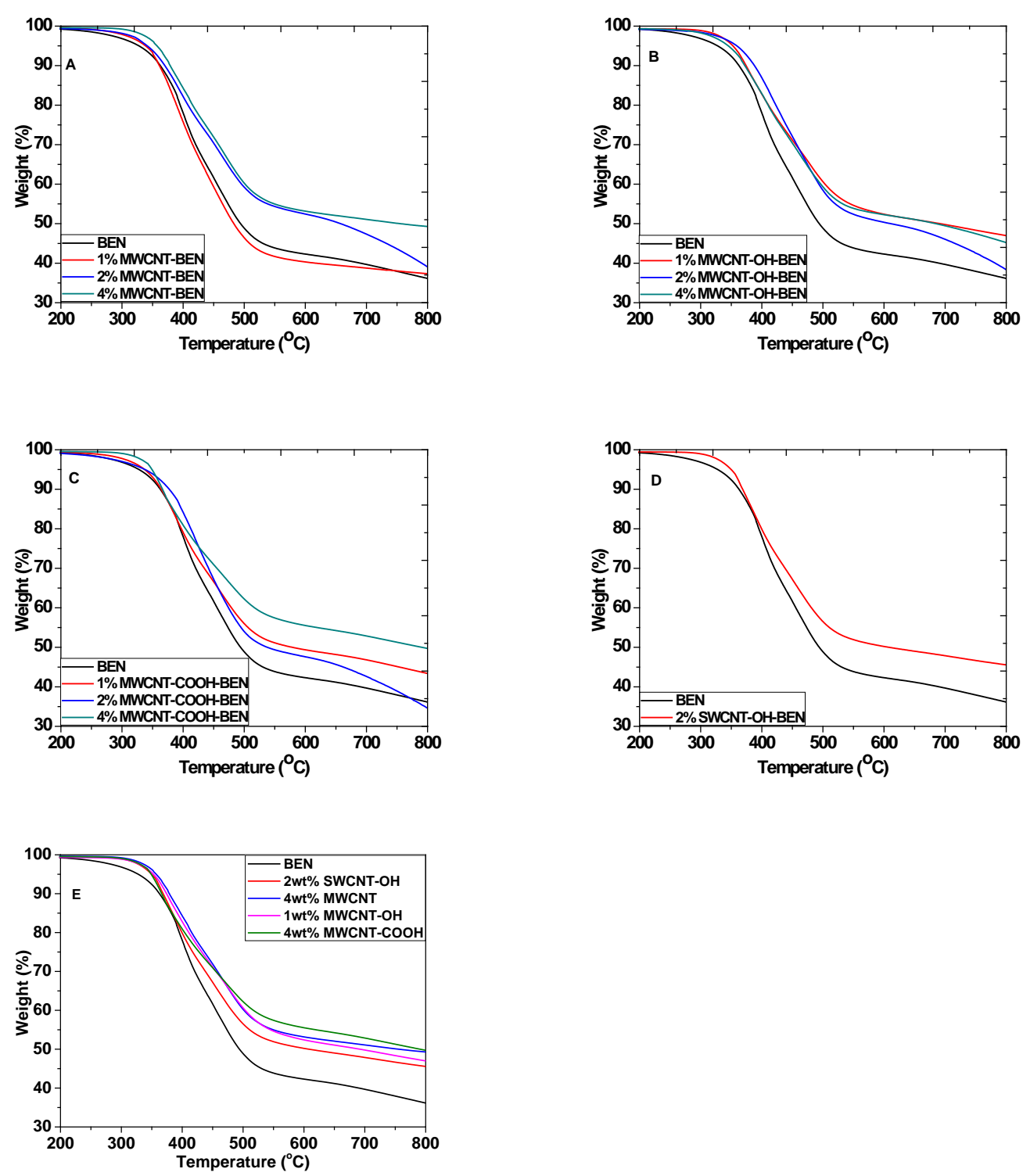

Figure 13: TGA results of BEN/CNT nanocomposites with residual weight in percentage vs. temperature (A) MWCNT/BEN, (B) MWCNT-OH/BEN, (C) MWCNT-COOH/BEN, (D) SWCNT-OH/BEN, and (E) comparative results under nitrogen atmosphere $(20 \mathrm{ml} / \mathrm{min})$. 
Table 10: experimental indicators for thermal stability from the TGA experiment.

\begin{tabular}{|l|l|l|l|}
\hline sample & $\mathrm{T}_{\mathrm{o}}$ & $\mathrm{T}_{1 / 2}$ & Char yield at $800{ }^{\circ} \mathrm{C}(\%)$ \\
\hline Pure BEN & 257 & 493 & 36 \\
\hline $1 \mathrm{wt} \%$ MWCNT/BEN & 292 & 483 & 37 \\
\hline $2 \mathrm{wt} \%$ MWCNT/BEN & 304 & 654 & 39 \\
\hline $4 \mathrm{wt} \%$ MWCNT/BEN & 331 & 752 & 49 \\
\hline $1 \mathrm{wt} \%$ MWCNT-OH/BEN & 319 & 677 & 47 \\
\hline $2 \mathrm{wt} \%$ MWCNT-OH/BEN & 310 & 599 & 38 \\
\hline $4 \mathrm{wt} \%$ MWCNT-OH/BEN & 295 & 677 & 45 \\
\hline $1 \mathrm{wt} \%$ MWCNT-COOH/BEN & 285 & 575 & 44 \\
\hline $2 \mathrm{wt} \%$ MWCNT-COOH/BEN & 253 & 532 & 34 \\
\hline $4 \mathrm{wt} \%$ MWCNT-COOH/BEN & 323 & 779 & 50 \\
\hline $2 \mathrm{wt} \%$ SWCNT-OH/BEN & 318 & 594 & 46 \\
\hline
\end{tabular}

Comparing with the TGA thermograms of the various BEN based nanocomposites under air atmosphere, it can be seen that 10\% POSS /BEN showed the best thermal stability below $567{ }^{\circ} \mathrm{C}, 4 \mathrm{wt} \% \mathrm{MWCNT} / \mathrm{BEN}$ nanocomposite became most thermally stable above $567{ }^{\circ} \mathrm{C}$. Interestingly, when comparing the TGA thermograms of the BEN based nanocomposites under nitrogen atmosphere, 5\% POSS-OH-BEN performed the best thermal stability.
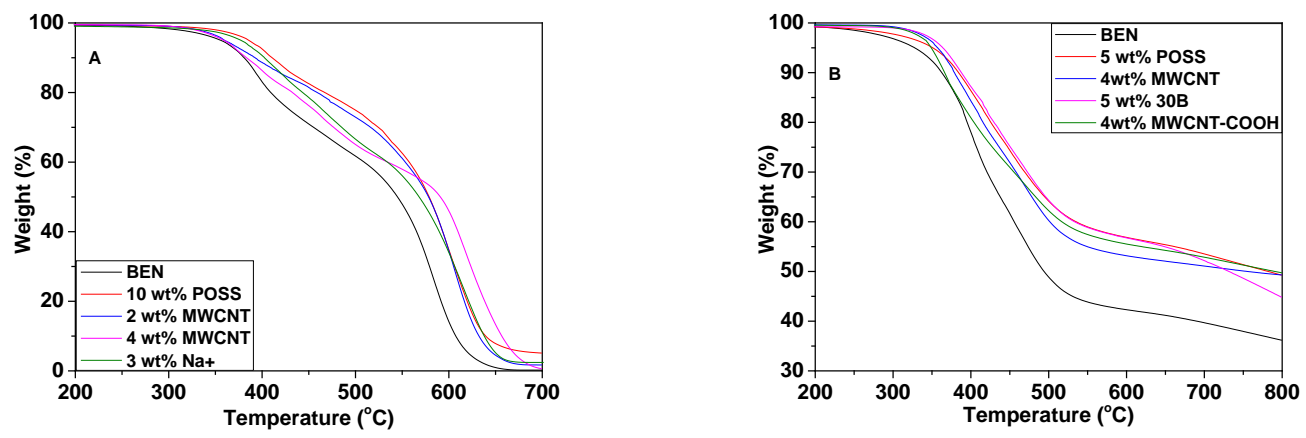

Figure 14: TGA results of BEN based nanocomposites with residual weight in percentage vs. temperature (A) under air atmosphere $(20 \mathrm{ml} / \mathrm{min})$, and (B) under nitrogen atmosphere $(20 \mathrm{ml} / \mathrm{min})$ 


\section{Conclusion}

For the BEN, the incorporation of nanofillers rarely showed a catalytic effect, except for CNTs. The cure of the BEN based mixtures can be monitored by means of FTIR. The cure of the BEN followed a ring opening mechanism. All the functionalised nanofillers examined reacted with the BEN during the cure. However, the reaction between the nanofillers and the BEN did not lead to an acceleration of cure. The incorporation of the nanofillers showed good improvement to the thermal stability of both BEN. For the BEN, 10\% POSS /BEN showed the best thermal stability below $567{ }^{\circ} \mathrm{C}, 4 \mathrm{wt} \% \mathrm{MWCNT/BEN}$ nanocomposite became most thermally stable above $567{ }^{\circ} \mathrm{C}$, under air atmosphere Interestingly, 5\% POSS/BEN exhibited the best thermal stability under nitrogen atmosphere.

\section{References}

1 Ghosh, N. N., Kiskan, B. \& Yagci, Y. Polybenzoxazines - New high performance thermosetting resins: Synthesis and properties. Prog Polym Sci 32, 1344-1391, doi:DOI 10.1016/j.progpolymsci.2007.07.002 (2007).

2 Nair, C. P. R. Advances in addition-cure phenolic resins. Prog Polym Sci 29, 401-498, doi:DOI 10.1016/j.progpolymsci.2004.01.004 (2004).

3 Lee, Y. H. \& Ishida, H. Probing the properties of particle-matrix interphase in reactive rubber-grafted polybenzoxazine resins by atomic force microscopy. Compos Interface 12, 481-499 (2005).

4 Jang, J. \& Seo, D. Performance improvement of rubber-modified polybenzoxazine. J Appl Polym Sci 67, 1-10 (1998).

5 Agag, T. \& Takeichi, T. Effect of hydroxyphenylmaleimide on the curing behaviour and thermomechanical properties of rubber-modified polybenzoxazine. High Perform Polym 13, S327-S342 (2001).

6 Lee, Y. H., Allen, D. J. \& Ishida, H. Effect of rubber reactivity on the morphology of polybenzoxazine blends investigated by atomic force microscopy and dynamic mechanical analysis. J Appl Polym Sci 100, 2443-2454, doi:Doi 10.1002/App.23430 (2006).

7 Ishida, H. \& Lee, Y. H. Infrared and thermal analyses of polybenzoxazine and polycarbonate blends. J Appl Polym Sci 81, 1021-1034 (2001).

8 Ishida, H. \& Lee, Y. H. Study of hydrogen bonding and thermal properties of polybenzoxazine and poly-(epsilon-caprolactone) blends. J Polym Sci Pol Phys 39, 736-749 (2001).

9 Ishida, H. \& Lee, Y. H. Synergism observed in polybenzoxazine and poly(epsilon-caprolactone) blends by dynamic mechanical and thermogravimetric analysis. Polymer 42, 6971-6979 (2001). 
10 Takeichi, T., Guo, Y. \& Agag, T. Synthesis and characterization of poly(urethane-benzoxazine) films as novel type of polyurethane/phenolic resin composites. J Polym Sci Pol Chem 38, 4165-4176 (2000).

11 Cui, Y. J., Chen, Y., Wang, X. L., Tian, G. H. \& Tang, X. Z. Synthesis and characterization of polyurethane/polybenzoxazine-based interpenetrating polymer networks (IPNs). Polym Int 52, 1246-1248, doi:Doi 10.1002/Pi.1051 (2003).

12 Ishida, H. \& Allen, D. J. Mechanical characterization of copolymers based on benzoxazine and epoxy. Polymer 37, 4487-4495 (1996).

13 Espinosa, M. A., Galia, M. \& Cadiz, V. Novel phosphorilated flame retardant thermosets: epoxy-benzoxazine-novolac systems. Polymer 45, 6103-6109, doi:DOI 10.1016/j.polymer.2004.07.002 (2004).

14 Rao, B. S., Reddy, K. R., Pathak, S. K. \& Pasala, A. Benzoxazine-epoxy copolymers: effect of molecular weight and crosslinking on thermal and viscoelastic properties. Polym Int 54, 1371-1376, doi:Doi 10.1002/Pi.1853 (2005).

15 Ishida, H. \& Ohba, S. Thermal analysis and mechanical characterization of maleimide-functionalized benzoxazine/epoxy copolymers. J Appl Polym Sci 101, 1670-1677, doi:Doi 10.1002/App.22499 (2006).

16 Huang, K. W. \& Kuo, S. W. High-Performance Polybenzoxazine Nanocomposites Containing Multifunctional POSS Cores Presenting Vinyl-Terminated Benzoxazine Groups. Macromol Chem Physic 211, 2301-2311, doi:DOI 10.1002/macp.201000362 (2010).

17 Agag, T. \& Takeichi, T. Preparation and cure behavior of organoclay-modified allyl-functional benzoxazine resin and the properties of their nanocomposites. Polym Composite 29, 750-757, doi:Doi 10.1002/Pc.20448 (2008).

18 Wang, Y. H., Chang, C. M. \& Liu, Y. L. Benzoxazine-functionalized multi-walled carbon nanotubes for preparation of electrically-conductive polybenzoxazines. Polymer 53, 106-112, doi:DOI 10.1016/j.polymer.2011.11.040 (2012).

19 Kamal, M. R. Thermoset Characterization for Moldability Analysis. Polym Eng Sci 14, 231-239 (1974).

20 Reading, M. \& Hourston, D. J. Modulated temperature differential scanning calorimetry : theoretical and practical applications in polymer characterisation. p.131 (Springer, 2006).

21 Lin, Y., Song, M., Stone, C.A. \& Shaw, S.J. A comprehensive study on the curing kinetics and network formation of cyanate ester resin/clay nanocomposites. Thermochim. Acta 552, 77-86 doi:DOI: 10.1016/j.tca.2012.11.009 (2013).

22 Kumar, K. S. S., Nair, C. P. R. \& Ninan, K. N. Rheokinetic investigations on the thermal polymerization of benzoxazine monomer. Thermochim Acta 441, 150-155, doi:DOI 10.1016/j.tca.2005.12.007 (2006). 